\title{
Study on Status Quo of Water Pollution Prevention \&Control Standard System for Ports and Vessels and Strategies
}

\author{
Wei Shen $^{1, \text { a) }}$, Guojing Xing ${ }^{* 2, \text { b) }}$ \\ ${ }^{1}$ China Waterborne Transport Research Institute, Beijing, 100088, China. \\ ${ }^{2}$ China Transport Telecommunication \& Information Center, Beijing, 100011, China. \\ a)shw3785@163.com \\ b)shw3787@163.com
}

\begin{abstract}
This paper starts with discussing the status quo of current port/vessel water pollution standard systems, compares port/vessel pollution prevention \&control laws and regulations of main ship-transport countries, analyzes main problems found present in current port/vessel water pollution prevention \&control laws and regulations, and finally aiming at these main problems, brings up strategies to establish port/vessel pollution prevention \&control standards.
\end{abstract}

\section{Introduction}

In recent years, with quickly growing global economy and continually increasing international import \&export trades of all countries, more and more domestic and foreign vessels arrive at and depart from ports of all countries more frequently and therefore vessels causes increasingly more serious pollution to ports. For these reasons, nations across the world have been increasingly emphasizing water pollution prevention \&control regarding ports and vessels, and made significant achievement in development and revision of standards and specifications concerning pollution prevention \&control. For port/vessel water pollution prevention \&control, however, current applicable standards are far far away from meeting the demand on current pollution prevention \&control.

Standardization is not only the basis for and the bridge between system and technology integrations, but also a guarantee to practical application of systems to a large range, and therefore plays a very important role in system establishment. At present, problems such as absence of standard systems, indefinite framework and unclear structure have been found in port/vessel water pollution prevention \&control, for instance, unified directions and coordination are absent in standard approval and development, standards contain repeated and overlapped contents, standards are not well-supported in the standard system, and the standard system is not 
updated in time. In terms of contents, standards are either excessively sporadic or of poor quality, and there are short of general and fundamental standards.

\section{Status quo of Port/Vessel Water Pollution Prevention \&Control Standards}

2.1 Status quo of the argument that whether vessels can discharge sewage in ports

Although international navigation vessels and some domestic-navigation vessels of flag countries are equipped with approved sewage treatment systems, in fact an awkward situation that vessel operators believe that their discharge is practically reasonable but the port authority does not permit to discharge often occurs. The question why the operators do not know what they should comply with and why the authorities do not know what law they should apply deserves our further investigation. Practically, for vessels installed with sewage treatment systems onboard, during their stay in ports the treatment systems are in normal operation, the treated sewage shall be at first discharged into the bilge water tank and then overflow out of the bilge after the tank is filled; sewage not treated or semi-treated is not permitted to be discharged to the bilge water tanks and then overflow out of the bilge because it does not meet the discharge requirements.

2.2 A vessel water pollution prevention \&control standard system is being established step by step.

In the current standard system planning classified by business fields, "the inland river vessel standard system" and "the environmental-protection standard system" are relevant to vessel water pollution prevention \&control. These two standard systems are short of standards directly concerning port/vessel water pollution prevention \&control. Additionally, in terms of standard classifications, both standard systems intersect and disorder mutually to some extent. Thus, establishing a separate port/vessel water pollution prevention \&control standard system is the top priority to direct and advance standardization work.

2.3 Some enacted standards have not been upgraded for long time and there are no critical technical standards.

As for vessel pollutant discharges, discharge standards aiming at related pollutants have already been inappropriate for growing modern ports. Also, even no laws, regulations and standards are available for building and configuration of facilities receiving and disposing of vessel pollutants, and port/vessel pollution prevention \&control standards have not been kept abreast with development of the era and science \&technology.

2.4 There is still a gap between the current port/vessel water pollution prevention \&control standards and laws \&regulations.

Currently, port/vessel water pollution prevention \&control standards are mandatory in most countries. According to international practices, all these standards shall be converted to compulsive technical regulations so that they are consistent with international practices on one hand and help improve relevant standards' legal status in order that "failing to meet the standard means breaking the law" is reflected in laws and regulations concerning port/vessel water pollutions on the other hand. 
2.5 Discharge standards on related pollutants are not consistent.

When traveling international waters, vessels shall comply with discharge standards specified in the international treaty Sewage Pollution Prevention Regulation. When navigating domestic waters, vessels shall comply with requirements specified in the domestic regulations of the country where it is traveling because most countries have made some reservations during accession to Sewage Pollution Prevention Regulation and therefore the international convention does not apply. For example, one of standards of China, Vessel Pollutant Discharge Standard (GB3552-83) specifies the requirements on vessel sewage discharge in China, and it applies to Chinese vessels and foreign vessels traveling Chinese waters. The detailed discharge requirements are shown in the table below:

\begin{tabular}{|c|c|c|c|}
\hline \multirow{2}{*}{ Item } & \multirow{2}{*}{ Inland } & \multicolumn{2}{|c|}{ Coastal } \\
\cline { 3 - 5 } & river & Within $4 \mathrm{~nm}$ from the nearest shoreline & $4 \sim 12 \mathrm{~nm}$ from the nearest \\
shoreline
\end{tabular}

It is known from this table that foreign-flag and China-flag vessels navigating international waters shall comply with the discharge requirements in Sewage Pollution Prevention Regulation, and China-flag vessels navigating domestic waters shall comply with the requirement in GB 3352-83, and therefore the standards to be complied with are inconsistent abnormally.

\section{Study and Compare Standard Systems of Other Main Ship-Transport Countries}

(1) The United States of America

Study mainly two aspects of water pollution discharge standard systems of U.S.A.: 1. Framework. The framework for the water pollution standard system of U.S.A. is presented as below: 


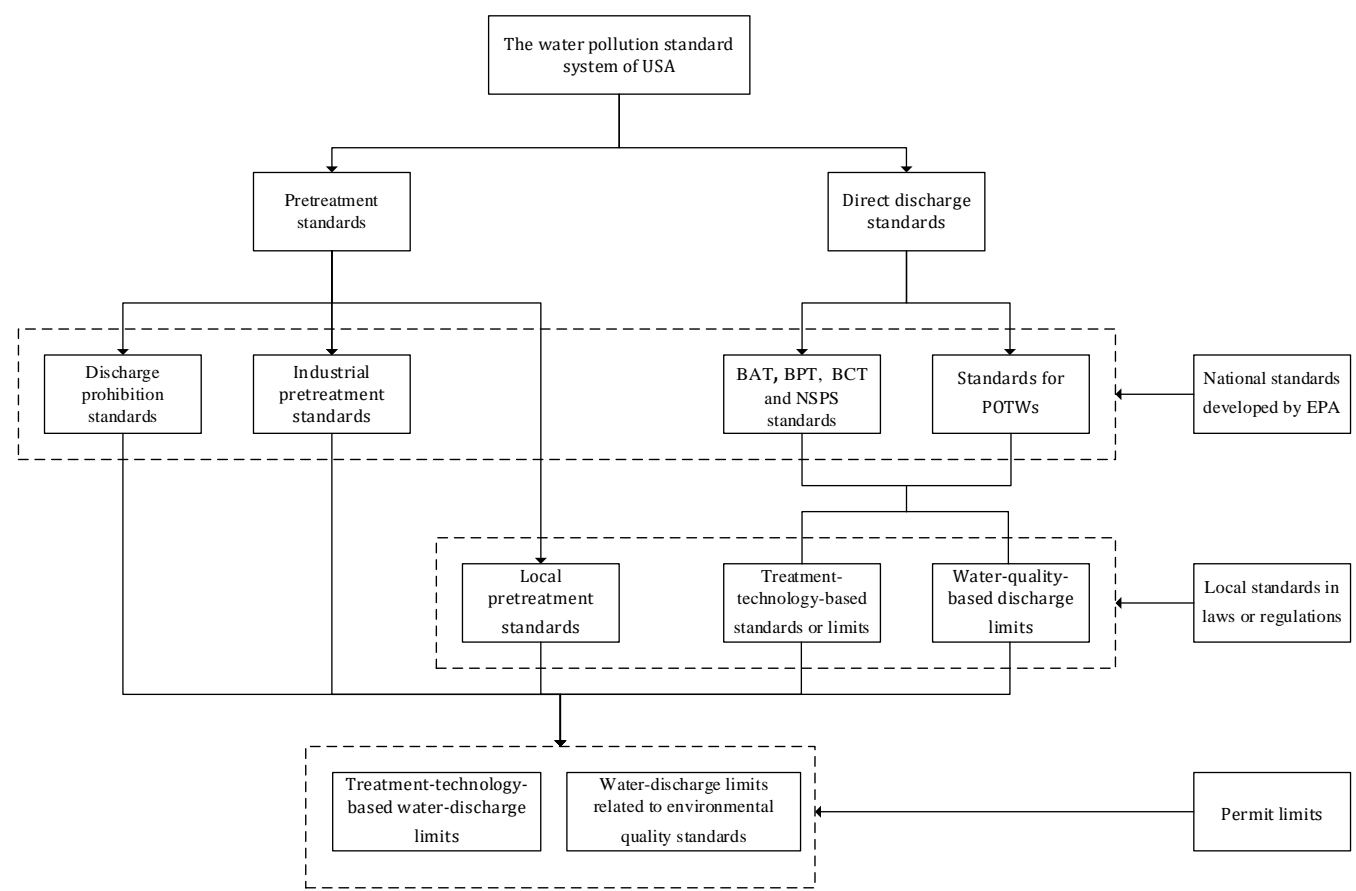

Figure 1 The framework for the water pollution standard system of USA

It is found from Figure 1 that in the U.S.A., most water pollution discharge standards and therefore corresponding pretreatment of water pollution discharge are industrial standards; different industries have their own industrial standards [1].

Study the content of the system. It is found from study that water pollution discharge standards have three levels: discharge ban, industrial pretreatment standards and local pretreatment standards, and the discharge limits and standards aim at different industries.

(2) European Union (EU)

EU is one of best regions with developed economy, best environmental quality and rich experience in water pollution prevention \&control in the world, and its framework of the water environmental standard system is presented below: 


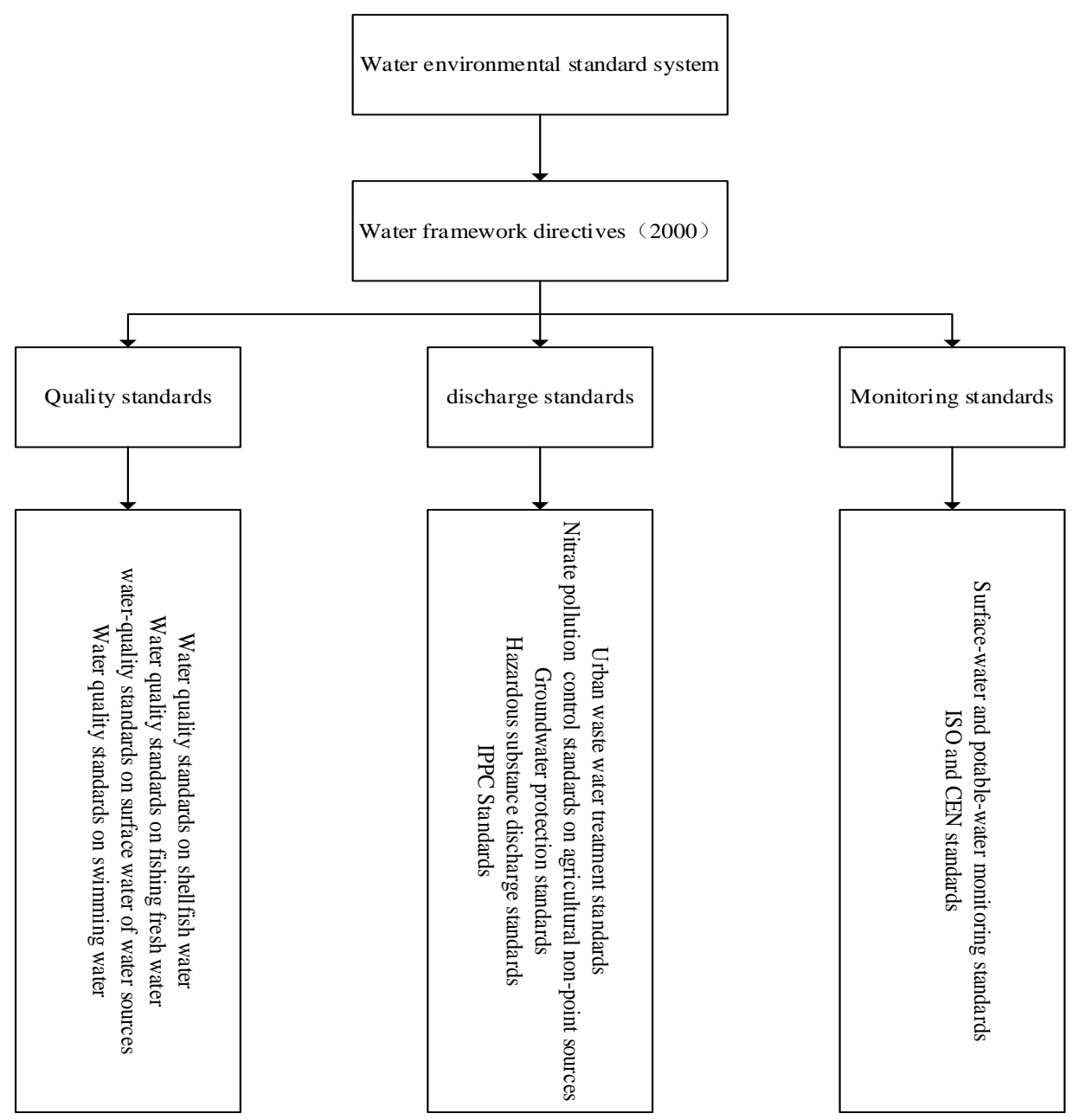

Figure 2 Water environmental standard system of EU

It is obvious that EU's water pollution prevention \&control standards involve every aspect such as quality, discharge and testing, EU has combined environmental quality management and discharge management to prevent and control pollution sources and set up a complete set of water environmental quality standards and discharge standards. EU tends to introduce flexible policies integrating prevention and control, and permits member states or regions to develop appropriate discharge standards subject to their respective conditions [2].

(3) China

By studying national water pollution discharge standard systems of China we found the following disadvantages: 1 . the system framework is incomplete, requirements on pretreatment standards are not definite and perfect, water pollution standards are defective to some degree, and shall be improved in terms of environmental management. 2. China's comprehensive discharge standards are inconsistent and inharmonious with industrial standards, the testing/monitoring methods are often defined later than the related standards, and improper methods are selected, and so on. 3. Economic policies are insufficiently supportive and helpful, and a complete and effective set of laws and regulations, e.g. water pollution prevention \&control standard systems, 
must be set up because applying administrative means to cope with water pollution has not been fit for development of the era any longer [3].

\section{Cause Analysis}

The disadvantages of the present port/vessel water pollution prevention \&control standard systems mainly result from incomplete management methods, supervision capability and policy systems, reflected in the following aspects:

(1) Environment management methods are single. For a long time, port/vessel water pollution discharge standards have been main methods to control pollution, standard systems have too heavy responsibilities for environmental protection. People have tried to do all works in accordance with the standards in order to reach their goal, this results in confused initial preparation of standards and on the contrary, their works are encountered with great difficulties.

(2) Supervision capabilities are different. Due to the imbalance in economic growth between all countries and regions, regional difference occurs in terms of port/vessel water pollution prevention \&control, and cannot be well-reflected during standard development. As a result, standards are developed in a confused way and in poor practical operability, and cannot be used effectively to manage water pollutant discharge [4].

(3) Technologies are not accumulated systematically. Technologies can be used as fundamental principle for standard development but for this purpose need to be researched and accumulated extensively for long-term. At present, technologic inputs and accumulations are short for industrial standards, some aspects such as standard limit setting and the range of standard management are poorly systematic, and the administrative guidance has much higher impact than the technical guidance.

\section{Strategies and Recommendations}

In conclusion, absence of port/vessel water pollution prevention \&control standard systems has not only affected development of related standards to a great extent but also led to no basis for relative water pollution prevention \&control, making practical operations difficult. The author believes that the following works have to be done to solve these problems:

(1) Study current related standards and regulations in the field of transportation and traffic to obtain those related to port/vessel water pollution prevention \&control and establish Ports \&Vessels Water Pollution Prevention \&Control Standard.

(2) Begin with studying port/vessel water pollution prevention \&control systems, solve practical problems present in existing standards in terms of vessel in-port water pollution prevention and control. The research shall be focused on problems, e.g. the standard coverage is incomplete, standards are out of date, connections are not tight enough, and standards are consistent with international standards, so as to establish a standard system 
covering every aspect, fit for development of the era and consistent with international standards [5].

(3) Do works related to port/vessel water pollution prevention \&control standard systems, such as classification, planning, revision recommendations and building planning.

(4) All countries shall push ahead to amend their respective domestic port/vessel water pollution prevention \&control standards in order to make them consistent with the international conventions. Those standards that were promulgated before, is out of date and is inconsistent with the amended international conventions must be adjusted based on the international conventions.

\section{Acknowledgments}

This work was financially supported by Special Funds for Basic Research and Operation Expenses of Ministry of Finance fund (2016QZ-HB060083).

\section{References}

1. Campbell-Mohn, Breen, Futrell, Sustainable Environmental Law, West PublishingCo., 1993, P.147.

2. United Stares Code, Title 33-Navigation and Navigable Waters, US Government printing office, Washington, 1991.

3. Citizen for a Better Environment V. Costle, 515F. Supp.264.

4. Maekenzieetal. NewScientist, 1999:162:18-19.

5. International Joint Comission and the Great Lakes Fishery Conunission. Exotie SPeeies and the ShiPPing Industry: The Great Lakes-St Lawrenee Eeosystem at Risk: a Special RePort to the Government of the United and Canada, 1990. 